\title{
Disorganisation in Social Gerontology
}

Usha Rani $\mathbf{K}^{*}$

Department of English, $K$ L University, Andhra Pradesh, India

*Corresponding author: Usha Rani K, Assistant Professor, Department of English, K L University, Andhra Pradesh, India, Tel: +919704448385; +919502852356; Email: usharavimuni@yahoo.com

Received: Mar 29, 2018; Accepted: Apr 06, 2018; Published: Apr 09, 2018

Copyright: ( 2018 Rani KU. This is an open-access article distributed under the terms of the Creative Commons Attribution License, which permits unrestricted use, distribution, and reproduction in any medium, provided the original author and source are credited.

\section{Description}

Social gerontology is the branch of geriatrics. Growing age is inevitable. Every stage of age has its own importance. The senior years are often viewed as a period of poor health, yet many older adults are capable of remaining active and busy well into their 80s and 90s. After 60 , a person feels, he has completed his work, responsibilities or duties. But the important aspect at this point is social interaction. At old age, the neurotransmitters and hormones disturbance cause dementia, osteoporosis, diabetes, hyper tension and common knee pain, low back ache, ankle pain, tremors, anxiety and depression are the common ailments they suffer with. Increased health concerns mark this period of development, and some individuals may experience mental declines related to dementia and Alzheimer's disease. Erikson also viewed the elder years as a time of reflection back on life. A gerontologist who studies the biological, psychological, and sociological phenomena of old age and aging will take care of old people by engaging them in social rehabilitation, sports, walking etc.

People go through many changes over the course of their lives. Development describes the growth of humans throughout their lifespan, from conception to death. Psychologists strive to understand and explain how and why people change throughout life. While many of these changes are normal and expected, they can still pose challenges that people sometimes need extra assistance to manage.

Social gerontology is the branch of geriatrics. Growing age is inevitable. Every stage of age has its own importance. We study old people their bodies, their perceptions, their motivations, their relationship to society and these topics are the subject matter of gerontology.

A person, who is under age 12 years, is considered as childhood where physical and mental development takes place. Their parents and teachers will help him to grow. This period of development is marked by both physical maturation and an increased importance of social influences as children make their way through elementary school. Kids begin to make their mark on the world as they form friendships, gain competency through schoolwork, and continue to build their unique sense of self.

Starting from 13 years to 19 years is called teenage. This period of life is often marked by forming and maintaining relationships. Forming bonds, intimacy, close friendships, and starting a family are often critical milestones during early adulthood. Those who can build and sustain such relationships tend to experience connectedness and social support while those who struggle with such relationships may be left feeling alienated and lonely. That is the decision-making age, where society influence, parental influence, and all other influences work on the person [1].
After that career, marriage, children start and continue up to the age of 40's and 50's and we call it as middle adulthood. This stage of life tends to center on developing a sense of purpose and contributing to society. Erikson described this as the conflict between generativity and stagnation. Those who engage in the world contribute things that will outlast them and leave a mark on the next generation emerge with a sense of purpose. Activities such as careers, families, group memberships, and community involvement are all things that can contribute to this feeling of generativity.

The person stabilizes at the age of 60 and later he is considered as retired. The senior years are often viewed as a period of poor health, yet many older adults are capable of remaining active and busy well into their 80s and 90s. Increased health concerns mark this period of development, and some individuals may experience mental declines related to dementia and Alzheimer's disease. Erikson also viewed the elder years as a time of reflection back on life. Those who are able to look back and see a life well lived emerge with a sense of wisdom and readiness to face the end of their lives, while those who look back with regret may be left with feelings of bitterness. After 60, a person feels, he has completed his work, responsibilities, or duties. But the important aspect at this point is social interaction. The children of that person might have settled in their lives and at this old age the person may be alone or with his spouse. At this stage, the people won't have energy of 20 or responsibility of 40 or stability of 50 . At old age the physical ability comes down, brain shrinks, and memory will be lost [2].

Human brain has 100 million neurons, 639 muscles and 206 bones. At old age, all these will gradually lose their strength. At old age, the neurotransmitters and hormones disturbance cause dementia, osteoporosis, diabetes, hyper tension and common knee pain, low back ache, ankle pain, tremors, anxiety and depression are the common ailments they suffer with. There are doctors, scientists, and friends, family persons to treat them or support them with necessary medication, practicing yoga, meditation etc. At 60 he never feels depressed or loneliness. He had the feeling that he feels all human relationships are illusionary. He knows the gross difference between illusion and he get acceptance. He starts getting satisfied with what he has. He feels contented with what he has.

Some people deal with stress by secluding themselves from social contact, spending time reflecting, and engaging in self-care activities. Clearly this does not imply that it is healthy to be involuntarily isolated from others, but consistent reports continue that people do spend less time with others as they age, and those who are able to enjoy this segment of their lives are better adjusted and have a greater sense of well-being. Research finds that disorganization occurs at differing rates and in different aspects of behavior. Other research indicates that it is the increased physical and social stress that can accompany aging, rather than age per se, that creates disorganization. 
Page 2 of 2

A gerontologist who studies the biological, psychological, and sociological phenomena of old age and aging will take care of old people by engaging them in social rehabilitation, sports, walking, writing story, poetry, gardening, meditation, participate in social activities. They have to be involved in Geriatric sports club, social activity club, geriatric food festival, geriatric movie hall, geriatric hospital, geriatric nursing homes, and geriatric ministry. The Government should release special funds to the geriatric people. Youth should respect them as part of Indian culture. That should be retained, sustained, elaborated, and enlightened.

Recent studies find it unnecessary for elders to maintain the same high degree of activity they had in middle age in order to have a high degree of self-esteem and life satisfaction in old age. Relationships and our need to be connected in order to maintain psychological wellbeing alter with time. In 1994, Lars Tornstam used the term gerotranscendence to refer to the elderly as selectively investing in some relationships over others, rather than comprehensively withdrawing. In his model, elders do seem to disengage, but do so more at will, choosing where their priorities lie and divesting themselves of superfluous relationships to focus on a more transcendent view of experience.
According to Quinnan in his study of elderly religious men:

Thus, the elderly demonstrate a higher degree of autonomy by dispensing with forms of social intercourse which have little value for them. This exercise of autonomy, rather than breaking connectedness, selectively enhances those relationships which the gero-transcendent find filled with meaning.

To combat the disorganization above considerations should be implemented. Then there is no point of geriatric disorganization and discrepancies. Everyone can live happily and do happily as everything is in our hands. In old age people have to develop correct thinking, right understanding and honest approach in order to develop amicability and acceptance which inturn gives satisfaction. Then the old people can get happiness so easily.

\section{References}

1. Butler RO (2008) The longevity Revolution - The benefits and challenges of living a long life. (1st edn) PublicAffairs Publications, USA.

2. Kiyakh HA (2010) S o ci al Gerantology, A Multidisciplinary Perspective. (9th edn) Pearson Publication, UK. 